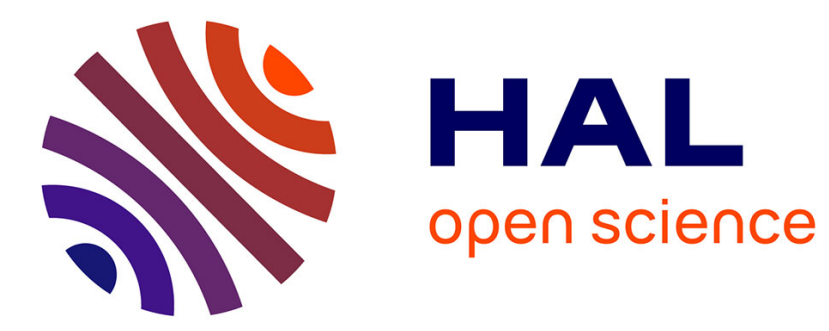

\title{
Stability of Self-Assembled Polymer Films Investigated by Optical Laser Reflectometry
}

\author{
J. Dejeu, S. Diziain, C. Dange, F. Membrey, D. Charraut, A. Foissy
}

\section{To cite this version:}

J. Dejeu, S. Diziain, C. Dange, F. Membrey, D. Charraut, et al.. Stability of Self-Assembled Polymer Films Investigated by Optical Laser Reflectometry. Langmuir, 2008, 24 (7), pp.3090-3098. 10.1021/la703307f . hal-00265972

\section{HAL Id: hal-00265972 \\ https://hal.science/hal-00265972}

Submitted on 28 Apr 2021

HAL is a multi-disciplinary open access archive for the deposit and dissemination of scientific research documents, whether they are published or not. The documents may come from teaching and research institutions in France or abroad, or from public or private research centers.
L'archive ouverte pluridisciplinaire HAL, est destinée au dépôt et à la diffusion de documents scientifiques de niveau recherche, publiés ou non, émanant des établissements d'enseignement et de recherche français ou étrangers, des laboratoires publics ou privés. 


\title{
Stability of Self-Assembled Polymer Films Investigated by Optical Laser Reflectometry
}

\author{
Jérôme Dejeu, ${ }^{\dagger}$ Séverine Diziain, ${ }^{\ddagger}$ Catherine Dange, ${ }^{\dagger}$ François Membrey, ${ }^{\dagger}$ \\ Daniel Charraut, ${ }^{\ddagger}$ and Alain Foissy* ${ }^{*} \uparrow$ \\ University of Franche-Comté, UTINAM Institut, Equipe Matériaux et Surfaces Structurés, CNRS-UMR \\ 6312, and FEMTO-ST Institut, Département d'Optique P.M. Duffieux, CNRS-UMR 6174, \\ 16 Route de Gray, 25030 Besançon Cedex, France
}

\begin{abstract}
We studied the influence of post-treatment rinsing after the formation of self-assembled polyelectrolyte films made with the weak base poly(allylamine hydrochloride) (PAH) and the strong acid poly(styrene sulfonate) (PSS). The stability of the film was studied using optical fixed-angle laser reflectometry to measure the release of polymeric material and AFM experiments to reveal the change of morphology and thickness. We found that the polymer films were stable upon rinsing when the $\mathrm{pH}$ was the same in the solution as that used in the buildup (pH 9). The films released most of the polymeric material when rinsed at higher $\mathrm{pH}$ values, but a layer remained that corresponded to a PAH monolayer directly bound with the silica surface. Films containing at least four bilayers were stable upon rinsing at lower $\mathrm{pH}$ values, but the stability of thinner films depended on the type of the last polymer deposited. They were stable in the case of PSS as an outermost deposit, but they released a large part of their material in the case of PAH. The stability results were determined using a simple model of the step-by-step assembly of the polymer film described formerly.
\end{abstract}

\section{Introduction}

Self-assembled polymer films (also called multilayer films) have received much attention since first described by Decher et al. in the early 1990s. ${ }^{1}$ They are easily obtained by the successive and alternate adsorption of two polyelectrolytes of opposite charges. In some cases, they are constructed with polymers bound via hydrogen bonds or a combination of electrostatic and hydrogen bonds. ${ }^{2,3}$ The plethora of recent papers and reviews addressing the buildup and the properties of these films has contributed much to our knowledge of the field. ${ }^{4}$ Given the broad range of materials and applications potentially available, there is every reason to pursue the study of macromolecular polymer assembly. ${ }^{5-7}$ Moreover, the layer-by-layer assembly process facilitates the elaboration of mixed or complex nanostructured materials containing small molecules, ions, proteins, DNA, or other particles. ${ }^{8-10}$ One of the most encouraging perspectives of polymer self-assembly is the design of membranes for the controlled release of medicinal or other active molecules by

* Corresponding author. E-mail: alain.foissy@univ-fcomte.fr; tel.: 03 816661 97; fax: 0381662033

¿ UTINAM Institut.

$\doteqdot$ FEMTO-ST Institut.

(1) Decher, G.; Hong, J. D.; Schmitt, J. Thin Solid Films 1992, 210-211, 831-935S

(2) Sukhisvili, A.; Granick, S. Macromolecules 2002, 35, 301-310.

(3) Cho, J.; Caruso, F. Macromolecules 2003, 36, 2845-2851.

(4) Decher, G.; Schlenoff, B. Multilayer Thin Films; Wiley VCH: Weinheim, Germany, 2003.

(5) Wu, A.; Yoo, D.; Lee, J. K.; Rubner, M. F. J. Am. Chem. Soc. 1999, 121, 4883-4891.

(6) Lvov, Y. M. Handbook for Surfaces and Interfaces of Materials, Nanostructure, Micelles and Colloids, Chapter 4, Lecture 1-6, Thin film nanofiltration by alternate adsorption of polyions, nanoparticles and proteins; Nahwa, H., Ed.; Academic Press: New York, 2001

(7) Cheung, J. H.; Fou, A. F.; Rubner, M. F. Thin Solid Films 1994, 244 985-989.

(8) Kharlampieva, E.; Izumrudov, Y. A.; Sukhishvili, S. A. Macromolecules 2007, 40, 3663-3668.

(9) Goulet, P. J. G.; dos Santos, D. S.; Alvarez-Puebla, R. A.; Oliveira, O. N.; Aroca, R. F. Langmuir 2005, 21, 5576-5591.

(10) Dejeu, J.; Buisson, L.; Guth, M. C.; Roidor, C.; Membrey, F.; Charraut, D.; Foissy, A. Colloids Surf., A 2006, 288, 26-35. tuning the permeation properties through the appropriate choice of the polymers and (or) the buildup procedure. ${ }^{11-15}$

Although much has been learned and debated regarding the main factors affecting the construction of polymer films using the layer-by-layer process, less attention has been given to their stability. It is, however, of crucial importance to address this aspect of the elaborated materials in view of their use and the development of new applications. Several studies have shown that polyelectrolyte films are sensitive to the modification of the environmental conditions, with respect to the conditions of the buildup of the film. This is the case with a change in $\mathrm{pH}$ when one polymer is a weak base or a weak acid, ${ }^{16}$ a change in salt content, ${ }^{13}$ or a change in temperature. ${ }^{17}$ Since the layer-by-layer process relies mostly on electrostatic binding between two oppositely charged macromolecules, one would expect the physicochemical parameters affecting electrostatic interaction forces to alter both the binding of the film to the surface and the cohesion of the film. However, the study of film stability is complicated by the largely irreversible character of interactions involving macromolecules, particularly in the case of the adsorption and complexation of polyelectrolytes, which are the two principal reactions involved in the growth of self-assembled polymer films.

Several papers ${ }^{16,18-20}$ have investigated the role of $\mathrm{pH}$ in the buildup of weak polyelectrolyte films, but few have addressed

(11) Gupta, N.; Patel, A. A.; Nassar, R.; Lvov, Y. M.; McShane, M. J.; Palmer, J. D. Colloids Surf., A 2004, 245, 137-142.

(12) Park, M. K.; Deng, S.; Advincula, R. C. Langmuir 2005, 21, 52725277.

(13) Dubas, S. T.; Schlenoff, J. B. Macromolecules 2001, 34, 3736-3740

(14) Ibarz, G.; Dähne, L.; Donath, E.; Möhwald, H. Chem. Mater. 2002, 14, $4059-4062$

(15) Chung, J.; Rubner, M. F. Langmuir 2002, 18, 1176-1183.

(16) Halthur, T. J.; Claesson, P. M.; Elofson, U. J. Am. Chem. Soc. 2004, 126 17009-17015.

(17) Serizawa, T.; Matsukuma, D.; Nanameki, K.; Uemura, M.; Kurusu, F.; Akashi, M. Macromolecules 2004, 37, 6531-6536.

(18) Boulmedais, F.; Bozonnet, M.; Schwinté, P.; Vogel, J. C.; Schaaf, P. Langmuir 2003, 19, 440-445.

(19) Burke, S. E.; Barrett, C. J. Biomacromolecules 2003, 4, 1773-1783. 
the effects of a change in $\mathrm{pH}$ after film buildup. The $\mathrm{pH}$-induced alterations of polymer films include a change in morphology, ${ }^{21}$ thickness, ${ }^{13}$ wettability; ${ }^{22}$ a release of part of the materials; ${ }^{23}$ and sometimes a complete destruction. ${ }^{24}$ Of course, the behavior depends on the polymers used but also on the construction process, film thickness, and sometimes the type of molecule last deposited ${ }^{25}$ or the deposition of a preliminary layer of polymers. ${ }^{26}$ The destruction of the multilayer films has been observed at low $\mathrm{pH}$ values for the polyelectrolyte pairs poly(methacrylic acid) (PMAA)-poly(4-vinyl pyrinide) quaternized (QPVP) ${ }^{27}$ and in acid and basic medium for PMAA/PVP ${ }^{28}$ and PMAA/PAH (polyallylamine, $\mathrm{HCl}) .{ }^{21,24}$ However, an increase in the molecular weight of the polyelectrolytes has been shown to prevent the destruction of the film but not the swelling. ${ }^{24}$

The stability of multilayers is of great interest in the study of encapsulated material release. ${ }^{29,30}$ Several studies have been devoted to this property by Sukhorukov et al., ${ }^{31-33}$ who made capsules in which the porosity of the membrane depended on the $\mathrm{pH}$ of the rinsing solutions. Upon change in $\mathrm{pH}$, the polyelectrolyte membrane switched back and forth between an open and a closed state for the release of Dextran molecules.

In the simple adsorption of a polymer layer, it has been shown that the amount adsorbed is not the same at a given $\mathrm{pH}$ whether the adsorption was made directly at that $\mathrm{pH}$ or via the release of an excess of polymer adsorbed at another $\mathrm{pH}$ where the molecules were weakly charged. ${ }^{34}$ The literature contains a large number of examples showing that polymer adsorption is either not or only partially reversible upon dilution of the bulk solution, change of salt content, change of $\mathrm{pH}$, etc. ${ }^{23,35,36}$ The stability of single polymer layers remains unclear; that of multistep deposited films is even more ambiguous.

The present paper addresses the stability of self-assembled polymer films formed with the weak base poly(allylamine hydrochloride) (PAH) and the strong acid poly(styrene sulfonate) (PSS) on silica. After construction at $\mathrm{pH} 9$ in $10^{-2} \mathrm{M} \mathrm{NaCl}$ solutions, the films containing a variable number of polymer layers were immersed in polymer-free solutions at different $\mathrm{pH}$ values. Alteration or destruction of the films was monitored using the evolution of a laser reflectometric signal in time. In addition, some samples were examined with AFM to determine the morphological changes.

(20) Hiller, J. A.; Mendelsohn, J. D.; Rubner, M. F. Nat. Mater. 2002, 1, $59-63$

(21) Biesheuvel, P. M.; Mauser, T.; Sukhorukov, G. B.; Möhwald, H. Macromolecules 2006, 39, 8480-8486.

(22) Kolasinska, M.; Warszynski, P. Appl. Surf. Sci. 2005, 66, 65-70.

(23) Hoogeven, N. G.; Cohen-Stuart, M. A.; Fleer, G.; Böhmer, M. R. Langmuir 1996, $12,3675-3681$.

(24) Mauser, T.; Dejugnat, C.; Mohwald, H.; Sukhorukov, G. B. Langmuir 2006, 22, 5888-5893.

(25) Leporatti, S.; Gao, C.; Voigt, A.; Donath, E.; Möhwald, H. Eur. Phys. J. E 2001, 5, 13-20.

(26) Kolasinska, M.; Krastev, R.; Warszynski, P. J. Colloid Interface Sci. 2007, 305, 46-56.

(27) Kharlampieva, E.; Sukhisvili, S. A. Langmuir 2003, 19, 1235-1243.

(28) Mauser, T.; Dejugnat, C.; Sukhorukov, G. B. J. Phys. Chem. B 2006, 110, 20246-20253.

(29) Sukhorukov, G. B.; Ferry, A.; Brumen, M.; Mohwald, H. Phys. Chem. Chem. Phys. 2004, 6, 4078-4089.

(30) Gaserod, O.; Sannes, A.; Skjak-Braek, G. Biomaterials 1999, 20, 773783.

(31) Sukhorukov, G. B.; Fery, A.; Brunnen, M.; Mohwald, H. Phys. Chem Chem. Phys. 2004, 6, 4078-4089.

(32) Antipov, A. A.; Sukhorukov, G. B.; Leporatti, S.; Radtchenko, I. L.; Donath, E.; Mohwald, H. Colloids Surf., A 2002, 198-200, 535-541.

(33) Dejugnat, C.; Sukhorukov, G. B. Langmuir 2004, 20, 7265-7269.

(34) van de Laat, A. W. M.; van den Heuvel, G. L. T.; Böhmer, M. R. Colloids

Surf., A 1995, 98, 61-71.

(35) Göbel, J. G.; Beeseling, M.; Cohen Stuart, M. A.; Poncet, C. J. Colloid Interface Sci. 1999, 209, 129-135.

(36) Roques Carmes, T.; Membrey, F.; Kaisheva, M.; Filiatre, C.; Foissy, A. J. Colloid Interface Sci. 2006, 299, 804-512.

\section{Materials and Methods}

Substrates. Oxidized silicon wafers with silicon oxide layers at different thicknesses (113 and $300 \mathrm{~nm}$, measured by ellipsometry, UVISEL Jobin Yvon) were purchased from ACM. The wafers were cleaned in piranha solution (1:3 v/v $\mathrm{H}_{2} \mathrm{O}_{2}$ and $\mathrm{H}_{2} \mathrm{SO}_{4}$ mixture) for $25 \mathrm{~min}$, then extensively rinsed with and stored in ultrapure water (Milli Q-Plus system, Millipore) until use.

Polyelectrolyte Solution. The polyelectrolytes used to build the polymer films were a weak base, poly(allylamine hydrochloride) (PAH, MW $=\sim 70 \mathrm{kDa}$ ), and a strong acid, poly(styrene sulfonate) (PSS, MW $=\sim 70 \mathrm{kDa}$ ), obtained from Sigma-Aldrich and Alfa Aesar, respectively. The refractive index increment of the PAH solutions was $\mathrm{d} n / \mathrm{d} c=0.2255 \mathrm{~cm}^{3} / \mathrm{g}$. The ionization ratio was about 0.4 at $\mathrm{pH} 9,{ }^{37}$ which is the $\mathrm{pH}$ for film construction. The refractive index increment of the PSS solution was $\mathrm{d} n / \mathrm{d} c=0.1707 \mathrm{~cm}^{3} / \mathrm{g}$. Refractive indices were determined with a Mettler Toledo refractometer RE50. The polyelectrolyte solution concentration was 0.01 $\mathrm{g} / \mathrm{L}$. A constant ionic strength $\left(10^{-2} \mathrm{M}\right)$ was maintained by the addition of an appropriate amount of $\mathrm{NaCl}$ in all experiments. The $\mathrm{pH}$ was adjusted with the $\mathrm{NaOH}$ and $\mathrm{HCl}$ solutions.

Optical Fixed-Angle Reflectometry. The reflectometer constructed in our laboratory was similar to that of Dijt et al. ${ }^{38}$ and the apparatus was described in a former report. ${ }^{39}$ Briefly, the reflectometer was equipped with an impinging jet cell into which the solution was injected through a cylindrical channel drilled into the prism. This geometry led to the formation of a stagnation point in the center of the cell to which the molecules are transported by convective diffusion. The polarized laser beam $(\mathrm{He}-\mathrm{Ne}, 632.8 \mathrm{~nm})$ reflected by the adsorbing substrate in the cell was decomposed by a beamsplitter in the parallel (p) and perpendicular (s) components with respect to the plane of incidence. The respective intensities $\left(I_{\mathrm{p}}\right.$ and $I_{\mathrm{s}}$ ) were measured with photodiodes, and the reflectometric signal $S$ was calculated from

$$
S=\frac{I_{\mathrm{p}}}{I_{\mathrm{s}}}
$$

Practically, the output was expressed as the ratio of $\left(S-S_{0}\right) / S_{0}$, which is usually related to the surface excess as follows: ${ }^{40}$

$$
\frac{S-S_{0}}{S_{0}}=\frac{\Delta S}{S_{0}}=\frac{\left(R_{\mathrm{p}} / R_{\mathrm{s}}\right)-\left(R_{\mathrm{p}} / R_{\mathrm{s}}\right)_{0}}{\left(R_{\mathrm{p}} / R_{\mathrm{s}}\right)_{0}}=A s \Gamma
$$

where $S_{0}$ and $S$ are the values of the signal defined in eq 1 when the polymer-free solutions are injected and in the course of the adsorption experiment, respectively. Eq 2 infers that $\Delta S / S_{0}$ is proportional to the surface excess $\Gamma\left(\mathrm{mg} \mathrm{m}^{-2}\right)$, as $\Gamma$ is a sensitivity coefficient that depends on several experimental parameters: ${ }^{40}$ the thickness and refractive index of the substrate, the refractive index increment of the polymer solution $(\mathrm{d} n / \mathrm{d} c)$, and the refractive index of the adsorbed layer $\left(n_{\text {ads }}\right)$.

In the cases of polyelectrolyte monolayer adsorption and after rinsing a self-assembled film at $\mathrm{pH} \mathrm{12,} \mathrm{the} \mathrm{reflectometric} \mathrm{output}$ could be converted into the deposited weight using the relation ${ }^{41}$

$$
\Gamma=\frac{1}{2 a}\left(-b+\sqrt{b^{2}+4 a\left(\frac{\Delta S}{S_{0}}-c\right)}\right)
$$

where $a, b$, and $c$ were determined for each $\mathrm{pH}$ after modeling of the interface.

(37) Petrov, A. I.; Antipov, A. A.; Sukhorukov, G. B. Macromolecules 2003, $36,10079-10086$.

(38) Dijt, J. C.; Cohen Stuart, M. A.; Hofman, J. E.; Fleer, G. J. Colloids Surf 1990, $51,141-158$.

(39) Roques-Carmes, T.; Membrey, F.; Filiatre, C.; Foissy, A. J. Colloid Interface Sci. 2002, 245, 257-266.

(40) Dijt, J. C.; Cohen Stuart, M. A.; Fleer, G. J. Adv. Colloid Interface Sci. 1994, 50, 79-101.

(41) Dejeu, J.; Foissy, A.; Membrey, F.; Balastre, M.; Bordes, B. Colloids Surf., A 2007, 310, 78-85. 
Table 1. Adsorption of PAH on Silica Wafer at Different pH Values $\left(\mathrm{NaCl} 1^{-2} \mathrm{M}\right)$ : Reflectometric Measurements

\begin{tabular}{ccccccc}
\hline $\mathrm{pH}$ & 4 & 5 & 9 & 10 & 11 & 12 \\
\hline$\Gamma\left(\mathrm{mg} \mathrm{m}^{-2}\right)$ & 0.10 & 0.13 & 0.47 & 0.51 & 0.58 & 0.11
\end{tabular}

AFM. AFM experiments were performed in a stand-alone SMENA scanning probe microscope (NT--MDT, SPM Accessories). AFM images were recorded for polymer films built at the stagnation point in constant force mode. During the scan, the deflection of the cantilever was maintained to a preset value by the feedback loop, and the topographic map of the surface was obtained by the vertical displacement of the scanner. Conical silicon tips were used on the AFM cantilevers. The force constant varied between 0.1 and 0.3 $\mathrm{N} / \mathrm{m}$ to probe the samples.

Experimental Procedures. Reflectometric measurements started with the injection of a $\mathrm{pH} 9$ polyelectrolyte-free solution containing $\mathrm{NaCl} 10^{-2} \mathrm{M}$ for $5 \mathrm{~min}$ to record $S_{0}$. The polyelectrolyte solutions were then injected alternately for $10 \mathrm{~min}$ to buildup the PAH/PSS films. No rinsing was done between adsorption steps. Since silicon oxide is charged negatively, ${ }^{42}$ the PAH solution was injected first.

At the end of the buildup, polymer-free solutions were circulated at different $\mathrm{pH}$ values but with the same salt concentration $(\mathrm{NaCl}$ $10^{-2} \mathrm{M}$ ). The rinsing steps lasted the time needed to reach a stationary value of the output.

\section{Results}

Elaboration of Polymer Films. Single Layer Adsorption of $P A H$ on Silica. The adsorption of a single layer of PAH on silica was measured in the reflectometric cell at different $\mathrm{pH}$ values from a polymer solution at a concentration of $10 \mathrm{mg} \mathrm{L}^{-1}$ and $\mathrm{NaCl} 10^{-2} \mathrm{M}$. The film was further rinsed with a PAH-free solution at the same $\mathrm{pH}$ and ionic strength, which did not induce any change in the output. The variation of the adsorption with $\mathrm{pH}$ reported in Table 1 revealed a maximum at $\mathrm{pH}$ 11, which is to be expected since the driving force for adsorption is mostly electrostatic. At low $\mathrm{pH}$ values ( $\mathrm{pH} 4$ ), the surface charge density of silica is very low and that of PAH is high; therefore, the adsorption is significantly lower than at $\mathrm{pH} 10$ where reverse conditions apply. The lower adsorption of $\mathrm{PAH}$ at $\mathrm{pH} 11$ and 12 can be explained by its lower charge density and lower screening capacity when compared to the small counterions $\mathrm{Na}^{+}$, which adsorb preferentially. The same adsorption trend was found for the weak polybase poly(vinyl imidazole) (PVI) on silica, with maximum adsorption at about $\mathrm{pH} 8{ }^{43}$ Note that it is difficult to compute the charge balance between adsorbate and substrate after completion of adsorption with precision since the known charge density of each isolated compound $\left(\mathrm{PAH}\right.$ and $\left.\mathrm{SiO}_{2}\right)$ increases significantly upon interaction. ${ }^{10}$

Five Bilayer Polymer Films. Films containing five bilayers were deposited on silica at different $\mathrm{pH}$ values in the reflectometric cell by the successive and alternate adsorption of PAH and PSS from solutions of each polymer containing also $\mathrm{NaCl}$ at a concentration of $10^{-2} \mathrm{~mol} \mathrm{~L}^{-1}$. These films were further rinsed by circulating a polymer-free solution at the same $\mathrm{pH}$ and salt concentration as the buildup system. All experiments were repeated 3 times and yielded similar results within a range of $5 \%$. Figure 1 presents the stepwise output of the reflectometer after each addition of a polymer solution. Since silica is negatively charged, the first polymer added was PAH. Considering that the step height is approximately proportional to the deposited amount, ${ }^{40}$ we can note that the deposited weight of the polymer

(42) Foissy, A.; Persello, J. Surface Groups Ionization and Complexation. In Surface Chemistry of Silicas; Legrand, A. P., Ed.; J. Wiley and Sons: New York, 1998; pp 365-414.

(43) Roques-Carmes, T.; Membrey, F.; Deratani, A.; Boehmer, M.; Foissy, A J. Colloid Interface Sci. 2002, 256, 273-283.

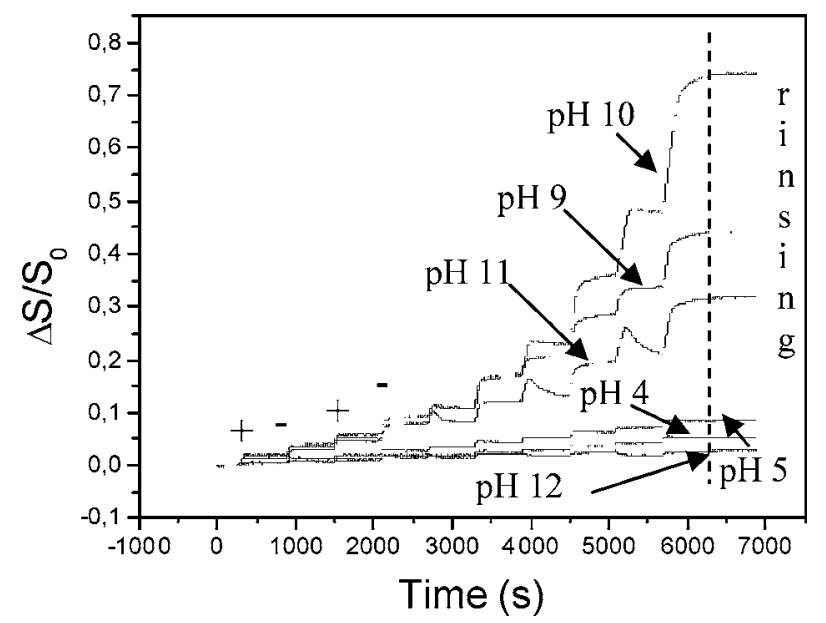

Figure 1. Variation of the reflectometric signal for the buildup of self-assembled films at different $\mathrm{pH}$ values. After construction, the films were rinsed at the same $\mathrm{pH}$ as the buildup.

varied considerably with the $\mathrm{pH}$, exhibiting a maximum at about $\mathrm{pH}$ 10. Again, this result is explained by the dependence on $\mathrm{pH}$ of the charge densities of PAH and silica. PSS is a strong acid that is fully ionized at all $\mathrm{pH}$ values explored in this investigation. In addition, PSS only binds with the positive PAH molecules; it does not adsorb directly on silica. Therefore, since the adsorption of PSS is limited to approximately the level of charge neutralization of the preceding deposited film, it is actually determined by the adsorption of $\mathrm{PAH}$, which means that the dependence of the film growth on $\mathrm{pH}$ follows from the dependence of the adsorption of PAH on silica in the first step.

Another feature in Figure 1 is the progressive increase of the deposited weight in the successive adsorption steps. This is clearly seen in higher steps for PSS at pH 9, 10, and 11 and it is illustrated and discussed in a previous work at $\mathrm{pH} 9 .{ }^{44}$ This phenomenon has been reported in several papers where distinction was drawn between a linear and an exponential growth of the film with the step number. ${ }^{45-47}$ In the first case, each polymer adsorbed the same amount in successive steps; in the second case, at least one of the two polymers progressively adsorbed an increasing amount. These different growth rates have been explained differently. ${ }^{4}$ Several investigations support that the progressive increase in adsorption of one polymer is caused by the diffusion of this polymer throughout the deposited film, ${ }^{48}$ rather than a straight deposition on the existing film, which would produce a constant deposited weight. In many cases, the stepwise growth of the film changes from exponential to linear. ${ }^{49}$ Our former investigation addressing the charge balance of PAH/PSS films on colloidal silica showed that PSS macromolecules bind with amine groups far inside the formerly deposited PAH layers, thus demonstrating the penetration of the last deposited PSS in the film. ${ }^{44}$ The same phenomenon did not appear to take place with PAH.

In the case of $\mathrm{PAH}$ at $\mathrm{pH} 11$, the reflectometric output sometimes presented a peculiar shape with a sharp increase and a slow decrease that lasted for most of the recording, about 10

(44) Diziain, S.; Dejeu, J.; Buisson, L.; Charraut, D.; Membrey, F.; Foissy, A. Thin Solid Films 2007, 516, 1-7.

(45) Decher, G. Science (Washington, DC, U.S.) 1997, 277, 1232-1237.

(46) Ruths, J.; Essler, F.; Decher, G.; Riegler, H. Langmuir 2000, 16, 88718878 .

(47) Schaaf, P.; Voegel, J.-C.; Lavalle, P. Proc. Natl. Acad. Sci. U.S.A. 2002, $99,12531-12535$.

(48) Elbert, D. L.; Herbert, C. B.; Hubbell, J. A. Langmuir 1999, 15, 53555362.

(49) Porcel, C.; Lavalle, P.; Decher, G.; Senger, B.; Voegel, J. C.; Schaaf, P. Langmuir 2007, 23, 1898-1904. 


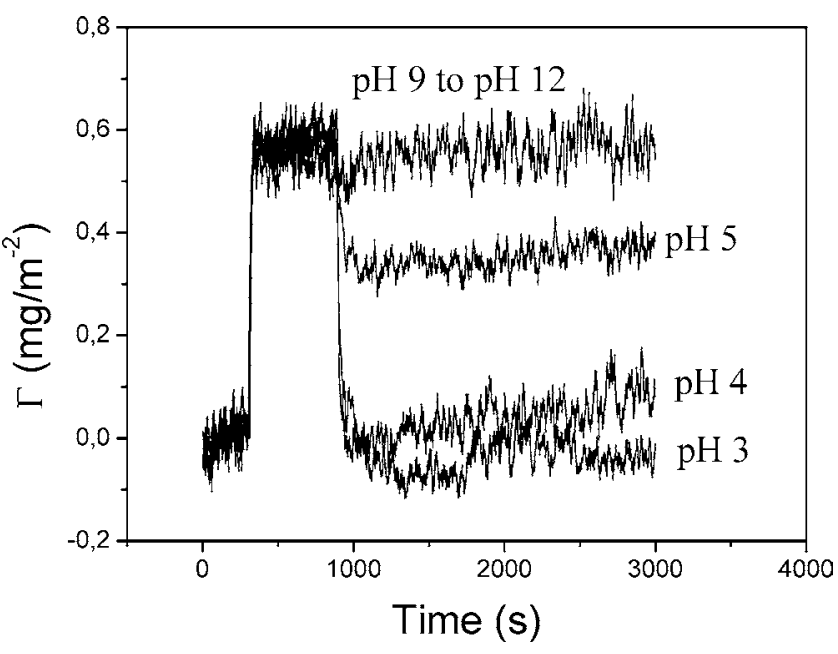

Figure 2. Reflectometric signal induced by rinsing with solutions at different $\mathrm{pH}$ values of a single $\mathrm{PAH}$ layer adsorbed at $\mathrm{pH} 9(\mathrm{NaCl}$ $10^{-2} \mathrm{M}$ in all measurements). The different traces correspond to the repetition of the experiments.

mn (Figure 1). These overshoots have been described in the literature, mentioning two principal causes: either a fast adsorption process followed by the dissolution of a polyelectrolyte complex ${ }^{50}$ or a slow rearrangement of the macromolecules in the film consecutive to the initial adsorption step. ${ }^{51}$ Both explanations make sense; however, parallel measurements using reflectometry and a quartz microbalance did not show any decrease in film weight during the overshoots. ${ }^{51,52}$ Moreover, recent calculations have revealed that the drift of the reflectometric output may result from an optical artifact related to the change of the refractive index and/or the thickness of the polymer film..$^{53,54}$ In our opinion, no desorption took place during the overshoot.

Stability of Polymer Films. Polymer Layers Rinsed at the Same $\mathrm{pH}$ and Ionic Strength as the Buildup. When rinsed with polymer-free solutions, at the same $\mathrm{pH}$ and salt concentration as the buildup, no alteration in reflectometric output was detected. All films were stable, which is reminiscent of the known irreversibility of the adsorption of single polymer layers. ${ }^{55}$ Similar observations have been reported in other investigations, which also showed that although the output signal was not affected by rinsing, it did induce a much higher adsorption in the subsequent steps, and the overshoots vanished. ${ }^{23}$

Polymer Layers Rinsed at Different $\mathrm{pH}$ Values as the Buildup $p H$. A single layer of PAH was adsorbed on silica at $\mathrm{pH} 9$, and then a polymer-free solution at different $\mathrm{pH}$ values was circulated in the cell. Figure 2 shows that the polymer layer was stable upon rinsing with a solution at $\mathrm{pH} 9$ (the buildup $\mathrm{pH}$ ) or above. Conversely, the polymer desorbed partially in more acidic solutions: the lower the $\mathrm{pH}$, the more it desorbed (Table 2). As stated previously, unless there is a significant contribution of specific interactions (i.e., nonelectrostatic binding forces), polyelectrolytes adsorb up to slightly above the neutralization of the surface charge. Thus, in these experiments, we found that

(50) Kovacevic, D.; van der Burgh, S.; de Keizer, A.; Cohen Stuart, M. A. Langmuir 2002, 18, 5607-5612.

(51) Wagberg, L.; Petterson, G.; Notley, S. J. Colloid Interface Sci. 2004, 274, $480-488$.

(52) Buron, C. C.; Filiatre, C.; Membrey, F.; Perrot, H.; Foissy, A. J. Colloid Interface Sci. 2006, 296, 409-418.

(53) Buron, C. C.; Filiatre, C.; Membre, F.; Bainier, C.; Charraut, D.; Foissy, A. J. Colloid Interface Sci. 2007, 314, 358-366.

(54) Dejeu, J. Films de deux polymers auto-assemblés: chlorhydrate de polyallylamine (PAH) et polystyrène sulfonate de sodium (PSS); mécanisme de croissance et stabilité. Ph.D. Thesis, University of Franche Comte, 2007.

(55) Fleer, G. J.; Cohen Stuart, M. A.; Scheutjens, J. M. H. M.; Cosgrove, T.; Vincent, B. Polymers and Interfaces; Chapman and Hall: London, 1993.
Table 2. Remaining Amount of Polymer after Rinsing a Single $\mathrm{PAH}$ Layer Formed in $\mathrm{NaCl} 10^{-2} \mathrm{M}$ Solution at $\mathbf{p H} 9$

\begin{tabular}{cccccc}
\hline rinsing $\mathrm{pH}$ & 3 & 4 & 5 & 9 & 12 \\
\hline remaining film wt $\left(\mathrm{mg} \mathrm{m}^{-2}\right)$ & 0 & 0.1 & 0.35 & 0.53 & 0.53
\end{tabular}

the desorption of PAH did indeed follow from the decrease in the silica charge density. Table 2 gives the remaining amount of polymer after rinsing: the polymer weight was calculated using the relation ( $\mathrm{pH} \mathrm{5)}$ and the appropriate values of the parameters $a-c .^{41}$

The stability of the film when rinsing with solutions at higher $\mathrm{pH}$ values behaves similarly to PVI on silica. ${ }^{36}$ Since the adsorbed amount is generally limited kinetically by an electrostatic barrier and not thermodynamically, it is process dependent. In many cases, as here, adsorption at a given $\mathrm{pH}$ is higher when it is obtained by the release of polymer adsorbed at a more favorable $\mathrm{pH}$ value than when it is adsorbed directly from the solution at that $\mathrm{pH}$. This phenomenon will be discussed further in the last section.

Stability of $\mathrm{SiO}_{2}(\mathrm{PAH} / \mathrm{PSS})_{x}$ Layers. PSS terminating films with different numbers of bilayers, $\mathrm{SiO}_{2}(\mathrm{PAH} / \mathrm{PSS})_{x}$, with $x$ varying between 1 and 5, were produced at $\mathrm{pH} 9$ and subsequently washed with polymer-free solutions at different $\mathrm{pH}$ values between 4 and 12 . The washing solutions contained the same concentration of $\mathrm{NaCl}\left(10^{-2} \mathrm{M}\right)$ as the buildup solution. To facilitate comparison, the outputs for a given value $x$ were set graphically at the same level at the end of the buildup (i.e., before beginning the rinsing experiments). In fact, the buildup experiments were highly reproducible: differences between the output in the last adsorption step did not exceed $5 \%$ for any film sequence.

The results in Figure 3 may be summarized as follows. Films were not stable when the $\mathrm{pH}$ of the rinsing solution was more basic than the buildup $\mathrm{pH}$; they released most of the macromolecules. On the contrary, no alteration in the films was detected upon rinsing with a solution that was more acidic than the buildup $\mathrm{pH}$. Assuming that the remaining polymer film was a single layer, after rinsing at $\mathrm{pH} 12$, the remaining polymer density was calculated from the final output and eq 3 . Values collected in Table 3 show a progressive increase with the number of bilayers in the film $(0.69,0.97,1.24$, and 1.72).

AFM pictures were consistent with the reflectometric observations. Figure 4 shows the typical morphology of a polymer film containing five bilayers deposited from polymer solutions at $\mathrm{pH} 9$ and $\mathrm{NaCl} 10^{-2} \mathrm{M}$. Films were characterized by a continuous polymer background with a mean thickness of about $13 \pm 3 \mathrm{~nm}$ and small thicker islands. ${ }^{44}$ In a former study, we showed that the islands contained aggregates of PAH/PSS complexes. ${ }^{44}$ The origin of the particular features of the film will be discussed in the last section. After rinsing at $\mathrm{pH} 4$, the picture showed no significant difference, as was to be expected from the stable reflectometric measurements, whereas rinsing at $\mathrm{pH} 12$ caused a considerable alteration in which most of the islands disappeared.

Stability of $\mathrm{SiO}_{2}(\mathrm{PAH} / \mathrm{PSS})_{x}$ PAH Layers. Similar experiments were performed with films ending with PAH instead of PSS; they can be written as $\mathrm{SiO}_{2}(\mathrm{PAH} / \mathrm{PSS})_{x} \mathrm{PAH}$, with $x$ varying between 1 and 4 . These films were also unstable (Figure 5and Table 3) upon rinsing at a $\mathrm{pH}$ above the buildup $\mathrm{pH}(\mathrm{pH} \mathrm{10-12)}$ and stable upon rinsing at a lower $\mathrm{pH}$, except in the case of films with three layers: $\mathrm{SiO}_{2}(\mathrm{PAH} / \mathrm{PSS})_{1} \mathrm{PAH}(12 \%$ weight loss $)$ and less so with five layers: $\mathrm{SiO}_{2}$ (PAH/PSS $)_{2} \mathrm{PAH}$ ( $2 \%$ weight loss). The remaining amount of polymer after rinsing at $\mathrm{pH} 12$ showed no specific trend with the film thickness $(0.93,0.52,0.92$, and 1.43). 

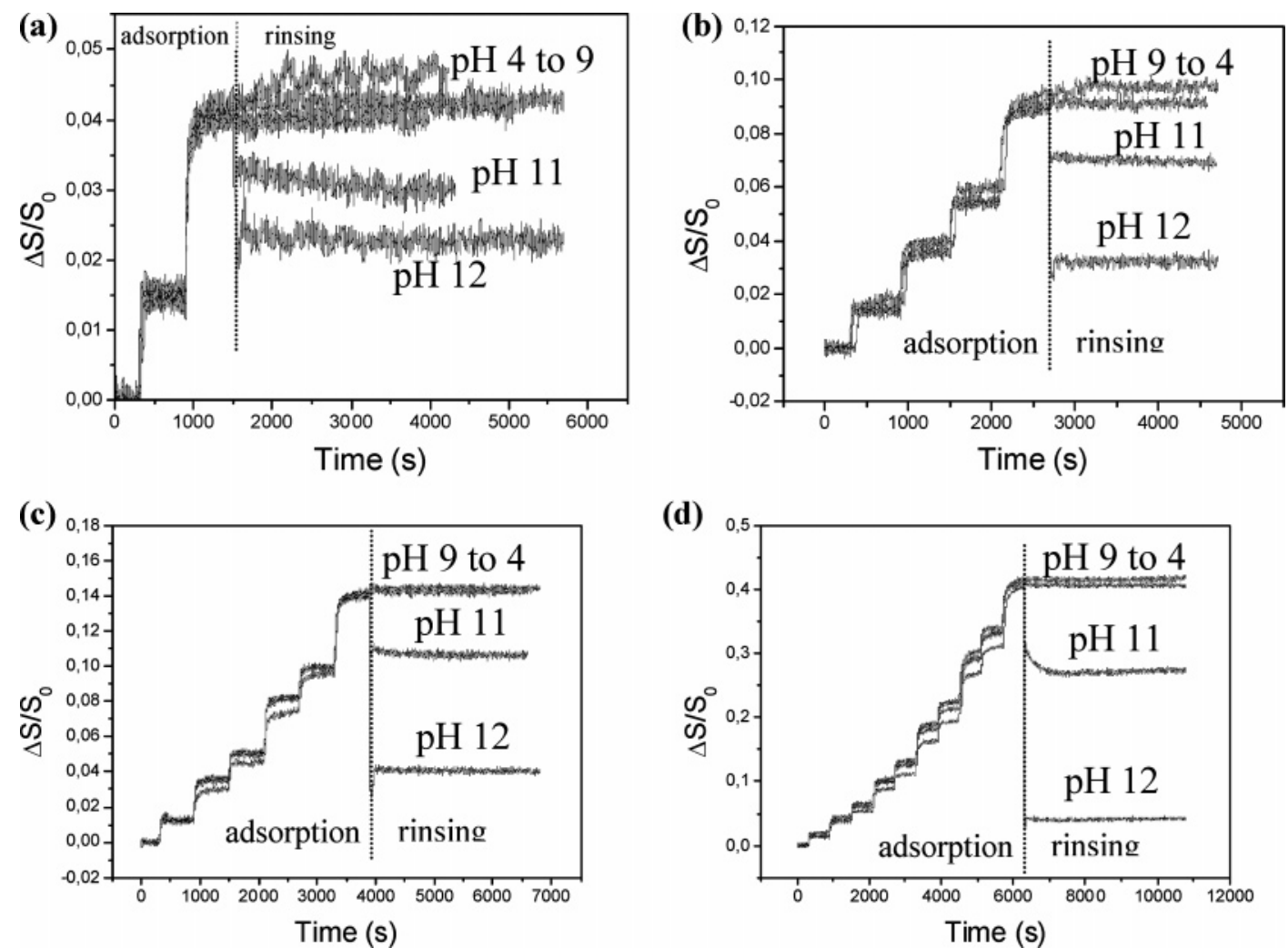

Figure 3. Reflectometric signals upon rinsing with solutions at different $\mathrm{pH}$ values of films containing: (a) one bilayer, (b) two bilayers, (c) three bilayers, and (d) five bilayers. All experiments in solutions of $\mathrm{NaCl} 10^{-2} \mathrm{M}$. The different traces correspond to the repetition of the experiments.

Table 3. Polymer Release (wt \%) and Remaining Weight (mg $\mathbf{m}^{-2}$ ) after Rinsing at Different $\mathbf{p H}$ Values of Films Built at $\mathbf{p H}$

\begin{tabular}{crrccc}
\hline & \multicolumn{5}{c}{$\mathrm{pH}$} \\
\cline { 2 - 6 } no. of layers & $4(\%)$ & $5(\%)$ & $9(\%)$ & $11(\%)$ & $12(\%)$ \\
\hline 1 & 100 & 34 & 0 & 0 & $0(0.53)$ \\
2 & 0 & 0 & 0 & 29 & $45(0.69)$ \\
3 & 12 & 2 & 0 & 18 & $44(0.93)$ \\
4 & 0 & & 0 & 26 & $63(0.97)$ \\
5 & 2 & 0 & 0 & & $87(0.52)$ \\
6 & 0 & & 0 & 25 & $71(1.24)$ \\
7 & 0 & 0 & 0 & & $77(0.92)$ \\
8 & 0 & & 0 & 27 & $75(1.72)$ \\
9 & 0 & 0 & 0 & & $86(1.43)$ \\
10 & 0 & & 0 & 33 & $90(1.24)$
\end{tabular}

${ }^{a}$ All experiments in $\mathrm{NaCl} 10^{-2} \mathrm{M}$ solution.

Reconstruction of Films after Rinsing at pH 12. Films with the composition $\mathrm{SiO}_{2}(\mathrm{PAH} / \mathrm{PSS})_{x} \mathrm{PAH}$ and $\mathrm{SiO}_{2}(\mathrm{PAH} / \mathrm{PSS})_{x+1}$ were prepared and then rinsed successively with a solution $\mathrm{NaCl}$ $10^{-2} \mathrm{M}$ at $\mathrm{pH} 12$ and 9. After stabilization of the output, a new solution of polyelectrolyte at $\mathrm{pH} \mathrm{9,} \mathrm{either} \mathrm{PAH} \mathrm{or} \mathrm{PSS,} \mathrm{was}$ introduced in the cell to attempt the reconstruction of the film broken at $\mathrm{pH} 12$. Figure $6 \mathrm{a}-\mathrm{d}$ shows the successive steps of the experiment for different film compositions ( $x=2$ or 3 ), the film construction, rinsing at $\mathrm{pH} 12$, rinsing at $\mathrm{pH} 9$, and the introduction of PAH or PSS. In the case of the film construction, the two stepwise curves corresponded to the repetition of the experiment, which aimed to test each of the polymer solutions. From Figure 6 , we see that only PSS could adsorb on the film that remained after the successive rinsing at $\mathrm{pH} 12$ and 9, which clearly means that this film was positively charged (i.e., contained an excess of PAH). In a more quantitative way, we see also that the output after PSS adsorption reached a roughly similar value in all experiments $\left(\Delta S / S_{0}=0.10\right.$, be aware of the different scales): approximately $3 \mathrm{mg} / \mathrm{m}^{2}$.

Discussion of Stability Experiments. The results of the stability experiments described previously are easily understandable given our current knowledge of the buildup of self-assembled polymer films. In a former study, we showed that there were two stages in the initial steps of film growth: the earlier one, during which the surface is active via the adsorption of $\mathrm{PAH}$, and the later one, during which growth relied solely on interactions between the two polymers. These two stages of the buildup are shown schematically in Figure 7 and will be outlined briefly next.

In the first stage, the adsorption of PAH is limited electrostatically, slightly above the neutralization of the surface charge of silica. ${ }^{10,55}$ At this point, the effective surface potential (streaming or zeta potential) is about $40 \mathrm{mV} .{ }^{10}$ An important feature at this stage is that a significant part of the surface remains polymerfree (Figure 7). In the second stage, PSS adsorbs only on the formerly deposited PAH macromolecules. It is also limited electrostatically, up to a surface potential near $-40 \mathrm{mV}$. Detailed investigations have shown PSS to bind with the free protonated groups of $\mathrm{PAH}$ after displacement of the $\mathrm{Cl}^{-}$counterions. It also binds with a large amount of newly ionized amine groups thanks to the additional protonation due to the electrostatic screening of PSS. At $\mathrm{pH}$ 9, we found that the binding with PSS increases the ionization of PAH to about $30 \% .{ }^{10}$ Finally, as suggested by Hoogeven et al., ${ }^{23}$ we presume that many of the bonds formed between PAH and silica surface in the first step break upon adsorption of PSS and free silanol groups to make new bonds in ensuing steps. Once bound, the two macromolecules form hydrophobic entities, much like they do in solution through a coacervation process. ${ }^{4} \mathrm{~A}$ few bonds between $\mathrm{PAH}$ and silica keep the complexes attached to the substrate. 

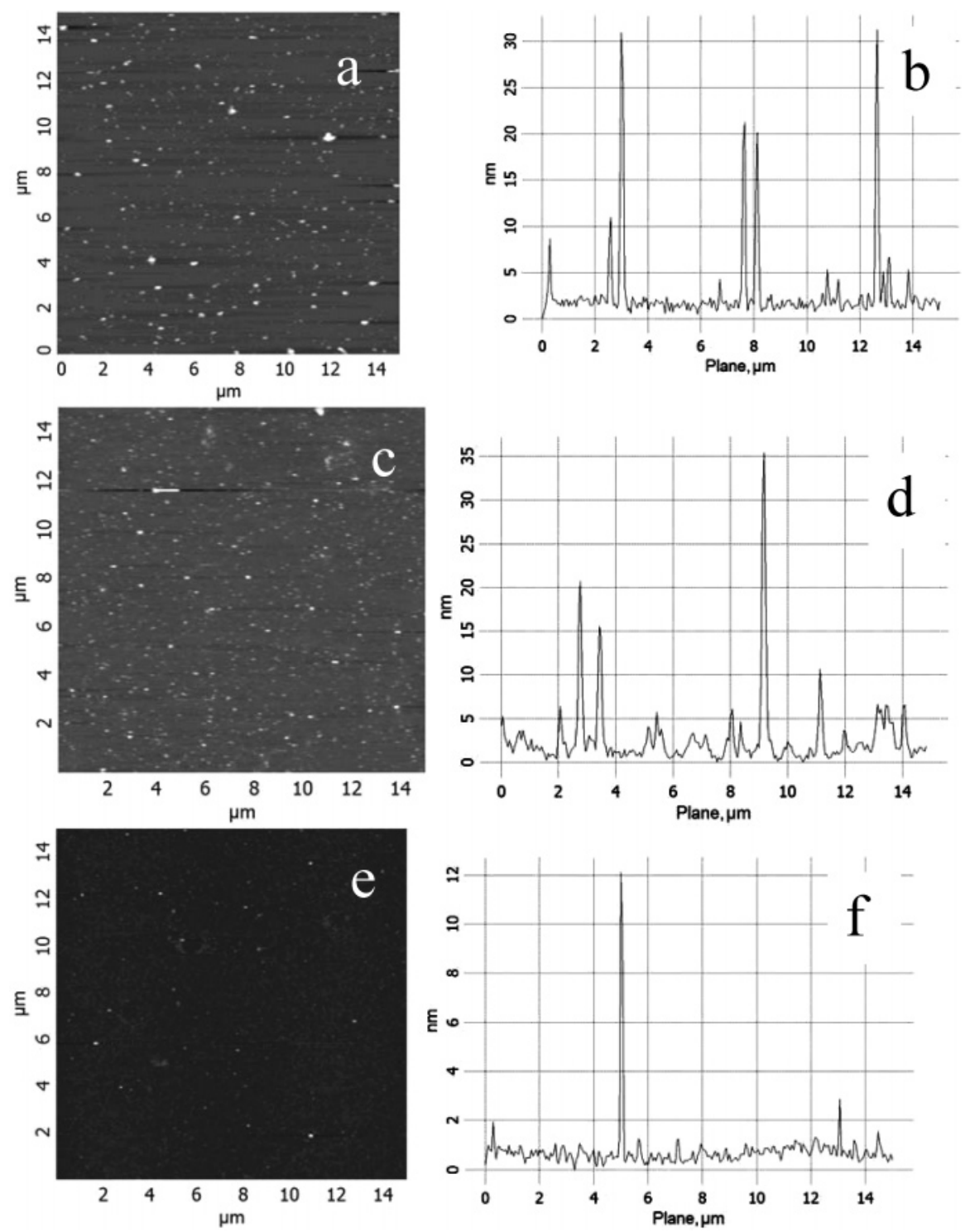

Figure 4. AFM contact mode topographic images of $\mathrm{SiO}_{2}$ (PAH/PSS) $)_{5}$ films. Effect of rinsing with $\mathrm{NaCl} 10^{-2} \mathrm{M}$ solution at different $\mathrm{pH}$ values and the corresponding $z$-profiles along an arbitrary horizontal line. (a and b) Film after buildup at $\mathrm{pH} \mathrm{9;} \mathrm{(c} \mathrm{and} \mathrm{d)} \mathrm{film} \mathrm{rinsed} \mathrm{at} \mathrm{pH}$ 4 ; and (e and f) film rinsed at $\mathrm{pH} 12$.
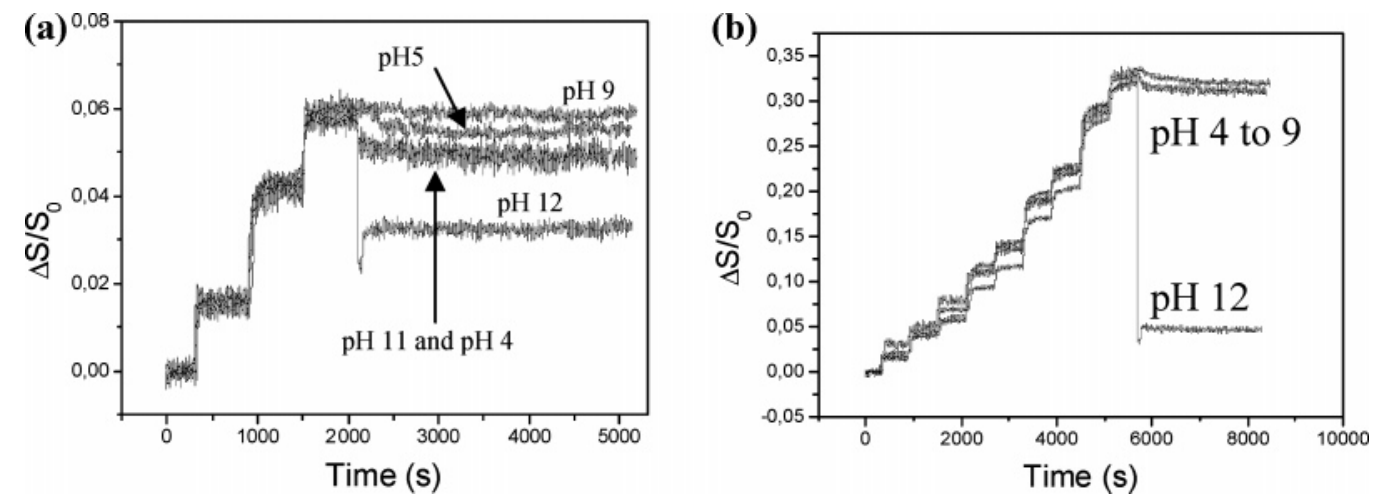

Figure 5. Reflectometric follow up of the buildup of films at $\mathrm{pH} 9$ and consecutive injection of the solutions at different $\mathrm{pH}$ values (NaCl $10^{-2-} \mathrm{M}$ ): (a) films containing three layers and (b) films containing nine layers. The different traces correspond to the repetition of the experiments.

In the third adsorption step, PAH binds both with unbound silanol groups and with sulfate groups pointing out of the macromolecular complexes. In the fourth step, again PSS may only bind with $\mathrm{PAH}$, enlarging existing $\mathrm{PAH}$-covered aggregates and forming new aggregates with the isolated PAH molecules deposited in the third step. The process continues until the entire silica surface is covered with macromolecular aggregates (step 6 in Figure 7). In subsequent stages, which constitute the second growth regime, the two polymers adsorb only via polymerpolymer interactions (i.e., the surface no longer contributes to the adsorption process). The transition step between the two growth stages depends on the many parameters influencing the 

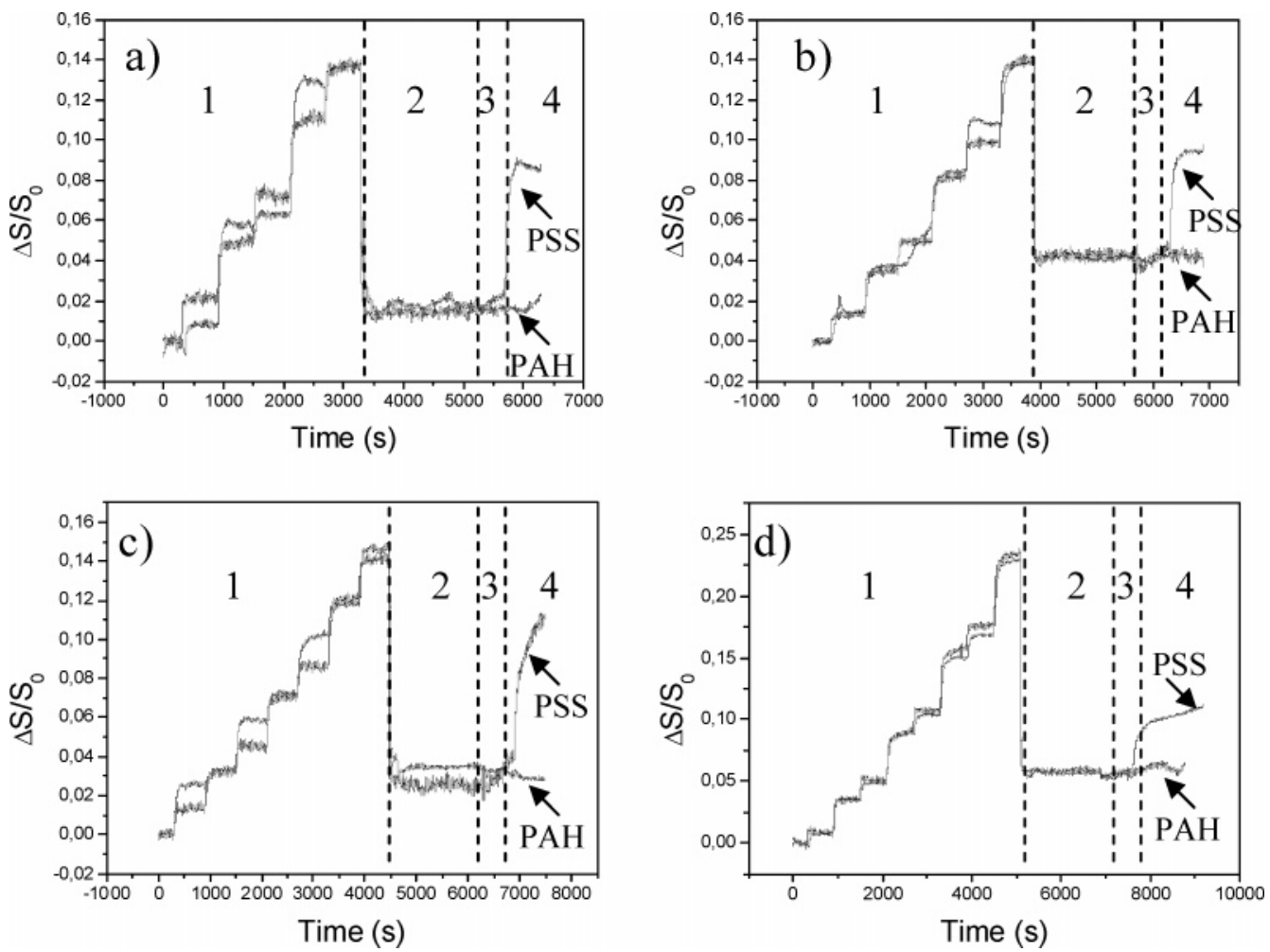

Figure 6. Reflectometic followup of the buildup of films at $\mathrm{pH} 9,{ }^{1}$ consecutive rinsing at $\mathrm{pH} 12^{2}$ and $\mathrm{pH} 9,{ }^{3}$ and injection of PAH and PSS solutions at $\mathrm{pH} 9 .{ }^{4}$ All experiments in $\mathrm{NaCl} 10^{-2} \mathrm{M}$ solutions. (a) $\mathrm{SiO}_{2}(\mathrm{PAH} / \mathrm{PSS})_{2} \mathrm{PAH}$, (b) $\mathrm{SiO}_{2}(\mathrm{PAH} / \mathrm{PSS})_{3},(\mathrm{c}) \mathrm{SiO}{ }_{2}(\mathrm{PAH} / \mathrm{PSS})_{3} \mathrm{PAH}$, and (d) $\mathrm{SiO}_{2}(\mathrm{PAH} / \mathrm{PSS})_{4}$. The different traces correspond to the repetition of the experiments.

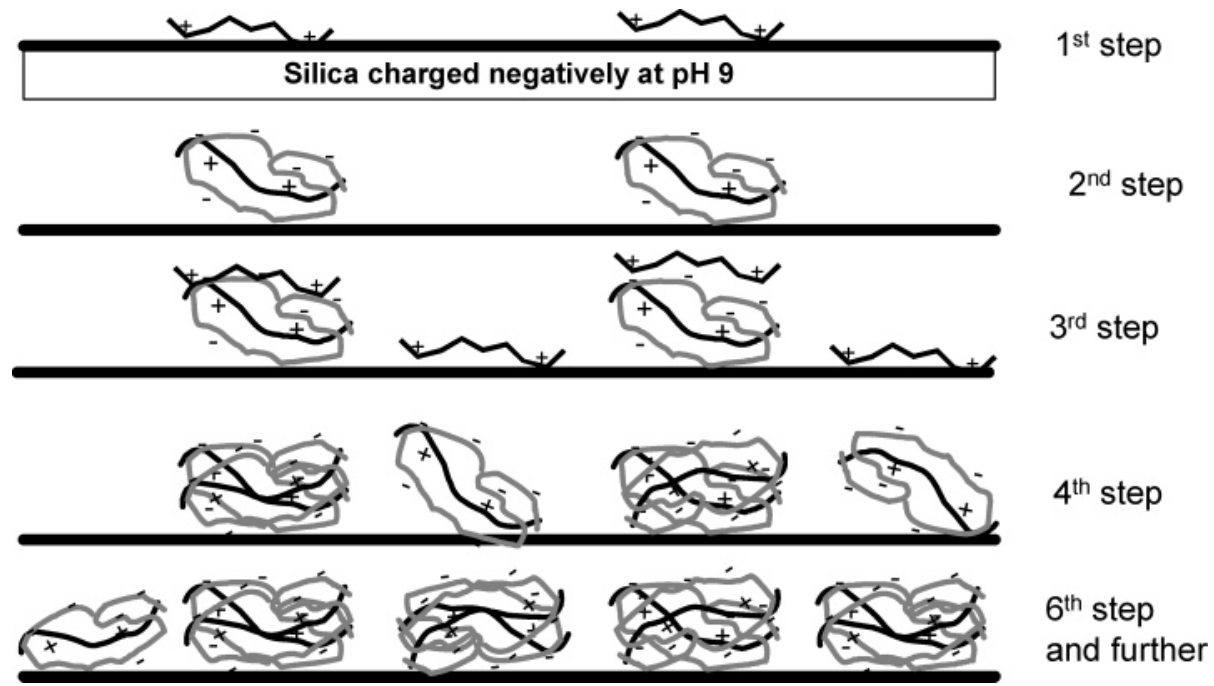

Figure 7. Sketch of the growth mechanism of the step-by-step self-assembly of two polyelectrolytes of opposite charge. Step 1: electrostatically limited adsorption of the positive polymer (PAH on silica). Step 2: formation of polymer complexes by adsorption of the negative polymer (PSS) on the first deposited PAH. Step 3: adsorption of the positive polymer on the polymer complexes PAH/PSS and on uncovered parts of silica. Step 4: adsorption of PSS on preformed PSS/PAH aggregates and formation of new pAH/PSS aggregates with isolated PAH molecules, etc. Step 6: the surface is completely covered with polymer aggregates, and further adsorption of the polyelectrolytes relies only on polycation-polyanion interactions.

polymer-surface and polymer-polymer interactions. In the case of PAH/PSS in $10^{-2} \mathrm{M} \mathrm{NaCl}$ solutions, the transition took place around step number $5 ;{ }^{54}$ in the case of Madquat/PAA polymers, we reported a transition between steps 4 and 6, depending on the $\mathrm{pH}$ and ionic strength. ${ }^{53}$ For the PSS-poly(methyl vinylpyridinium) $(\mathrm{PVP}+)$ pair, Hoogeven et al..$^{23}$ found a transition beyond the third layer on $\mathrm{TiO}_{2}$ and the sixth layer on $\mathrm{SiO}_{2}$. AFM images (Figure 5) are consistent with the mechanism described previously: aggregates show up as small islands that vary in size and number at each adsorption step. ${ }^{44}$ The mechanism described previously was well-illustrated by Picart et al. in the buildup of films with poly(L-lysine) and hyaluronic acid on glass. ${ }^{56}$

With this knowledge in mind, we now discuss the results obtained in the present investigation. Concerning the first PAH layer, as stated previously, the system behaved as expected from the principle that polyelectrolyte adsorption is limited for

(56) Picart, C.; Lavalle, P.; Hubert, P.; Cuisinier, F. J. G.; Decher, G.; Schaaf P.; Voegel, J.-C. Langmuir 2001, 17, 7414-7424. 
kinetic reasons at the level of surface charge neutralization. ${ }^{57,58}$ Since lowering the $\mathrm{pH}$ decreased the surface charge density, part of the PAH molecules desorbed, leaving nearly the required amount for charge neutralization. When rinsing at $\mathrm{pH} \mathrm{3}$, all molecules deposited at $\mathrm{pH} 9$ left the surface since it was uncharged at this $\mathrm{pH}$ value. At $\mathrm{pH} 4$ and 5, the remaining amount of $\mathrm{PAH}$ was 0.1 and $0.35 \mathrm{mg} \mathrm{m}^{-2}$, respectively (accuracy $5 \%$ ). However, although the isolated PAH molecules were not charged, they remained adsorbed after rinsing at $\mathrm{pH} 12$. There is an interesting point to mention here: in the case of direct adsorption of PAH at $\mathrm{pH} 12$, the amount adsorbed was $0.11 \mathrm{mg} \mathrm{m}^{-2}$ (Table 1), which is significantly lower than the amount remaining on the film made at $\mathrm{pH} 9$ after rinsing at $\mathrm{pH} 12\left(0.5 \mathrm{mg} \mathrm{m}^{-2}\right)$. The same phenomenon has been described for the adsorption on silica of another weak polybase: PVI. ${ }^{36}$ We found that PVI adsorbed about $40 \%$ less from a solution at $\mathrm{pH} 10$ than via the release at $\mathrm{pH} 10$ of the excess of polymer adsorbed at $\mathrm{pH}$ 8. This phenomenon was explained by a kinetic phenomenon associated with the time required to detach and rearrange the entangled chains of the polymer. There is much evidence from the literature that polyelectrolyte adsorption is controlled kinetically, via the formation of an electrostatic barrier between the deposited molecules and those coming from the solution. ${ }^{35,57}$ One consequence is the lack of reversibility and a large dependence of the polymer uptake on the experimental protocol, as we see here. Instead, when the $\mathrm{pH}$ was switched from the buildup at $\mathrm{pH}$ 9 to $\mathrm{pH} 4$ and 3, the release of PAH was immediate because the charge density of the PAH molecules increased strongly, which created an expelling force by electrostatic repulsion.

Films of higher ranks (four adsorption steps and above) built at $\mathrm{pH} 9$ were stable when the $\mathrm{pH}$ was lowered, but they released part of the macromolecules in more basic media, which was contrary to the behavior of the PAH monolayer. The stability in acidic media is explained by the cohesive strength of the macromolecular aggregates. When the $\mathrm{pH}$ was switched to lower values, the charge density of PAH increased and so, consequently, did the number of electrostatic bonds between PSS and PAH (for isolated macromolecules, the amine groups are totally protonated at about $\mathrm{pH} 7$ and below). Although no bonds were expected between $\mathrm{PAH}$ and silica at $\mathrm{pH} 4$ and below (shown previously by the total desorption of the single PAH layer), the hydrophobic PAH/PSS aggregates were not released from the interface due to the cohesive strength of the whole polymer film.

Conversely, the film broke at a $\mathrm{pH}$ higher than the buildup $\mathrm{pH}$, due to the decrease in the charge density of PAH and the corresponding decrease in the bonds between PAH and PSS. In addition to the lower binding strength, the negative charge of PSS turned in large excess of the positive charge of PAH, which induced electrostatic repulsion between PSS molecules and with the negative silica surface. Therefore, one is inclined to think that the signal's decrease reveals the desorption of both kinds of molecules. The remaining amount of polymer showed no particular trend; it varied erratically between 0.5 and $1.4 \mathrm{mg}$ $\mathrm{m}^{-2}$, which was the same or significantly higher than the single layer of $\mathrm{PAH}$ adsorbed at $\mathrm{pH} 9\left(0.53 \mathrm{mg} \mathrm{m}^{-2}\right)$. We did show that the single layer of $\mathrm{PAH}$ formed at $\mathrm{pH} 9$ was stable upon rinsing at $\mathrm{pH}$ 12, which we attribute to the electrostatic bonds remaining at this $\mathrm{pH}$, owing to the charge induced on $\mathrm{PAH}$ by its interaction with silica and to the long time required to rearrange and release the excess of entangled macromolecules. In comparison, selfassembled polyelectrolyte films were not stable upon rinsing at

(57) Cohen Stuart, M. A.; Hoogendam, C. W.; de Keizer, A. J. Phys.: Condensed Matter 1997, 9, 7767-7783.

(58) Geffroy, C.; Labeau, M. P.; Wong, K.; Cabane, B.; Cohen Stuart, M. A. Colloids Surf., A 2000, 172, 47-56.

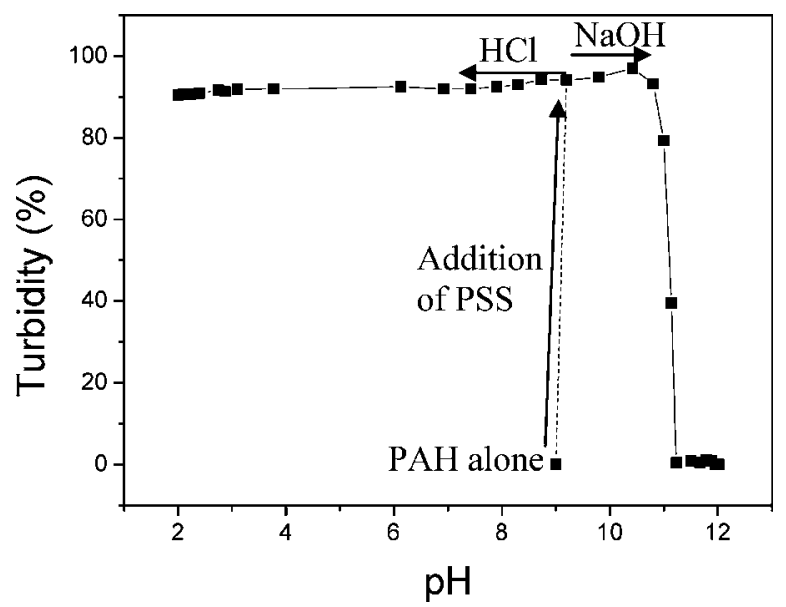

Figure 8. Turbidimetric followup of the influence of $\mathrm{pH}$ on the stability of PAH/PSS aggregates formed at $\mathrm{pH} 9$ in solutions containing $\mathrm{NaCl} 10^{-2-} \mathrm{M}$. Change of $\mathrm{pH}$ with $\mathrm{NaOH} 1 \mathrm{M}$ or $\mathrm{HCl}$ $1 \mathrm{M}$.

$\mathrm{pH} 12$, but the remaining amount was at least that found for a single PAH layer. After destruction of the film at $\mathrm{pH} 12$ and rinsing at $\mathrm{pH}$ 9, the attempts of adsorption, showing that PSS only can adsorb on the remaining film, show that this film was positively charged and very likely was a PAH layer directly bound with silica. We presume that the PAH/PSS aggregates forming the film (Figure 7) broke up when the electrostatic bonds became too low, due to the decrease in charge of PAH at higher $\mathrm{pH}$ values. As shown elsewhere, $4,21,23,24,27,28$ there is a critical polymer charge density below which polyelectrolyte films or aggregates do not form; therefore, in the case of weak polyelectrolytes, which are $\mathrm{pH} / \mathrm{ch}$ arge dependent, there should be a critical $\mathrm{pH}$ for the stability domain. To illustrate more clearly the role of disaggregation in the film rupture, we prepared a mixture of the two polymers at $\mathrm{pH} 9$ in the same conditions as the buildup in the reflectometric cell. As expected, the system was highly turbid, due to the formation of PAH/PSS aggregates. We did not characterize the precipitated units, we merely added a concentrated $\mathrm{NaOH}$ solution stepwise, under strong magnetic stirring, to raise the $\mathrm{pH}$ and measured the turbidity of the system continuously. Figure 8 shows that the suspension did indeed become perfectly clear at $\mathrm{pH} 12$ (i.e., aggregates broke, and the two polymers dissolved completely).

An interesting feature was observed in the earlier steps of growth (see Table 2). Films ending with a PSS layer were completely stable in acidic media, whereas films ending with PAH released part of their content: $12 \mathrm{wt} \%$ after step 3 and 2 wt $\%$ after step 5. No release was detected upon acidification at step 7 and above. This is explained by the growth mechanism sketched in Figure 7. When PAH was the last layer deposited, a fraction of the molecules had adsorbed as discrete units on the silica surface, as illustrated by step 3 (or step 5, not shown) in Figure 7. Thus, when the solution became more acidic, a fraction of the isolated PAH desorbed upon electrostatic repulsion since the charge density of silica decreased and that of PAH increased. The same phenomenon took place in the desorption from a single layer of PAH in Table 2. In steps 2 and 4, there was no release of polymer from the film since all PAH molecules formed insoluble aggregates with PSS. As stated previously, polyelectrolyte aggregates are stable upon a decrease in $\mathrm{pH}$ since the binding strength of the polyelectrolyte complexes increases with the related increase of the charge density of PAH. Finally, we see that the stability of the PAH/PSS films is easily explained by the stepwise growth sketched in Figure 7, which is also 
consistent with AFM pictures in Figure 5 and other film characteristics described in former investigations. ${ }^{10,44}$ As expected, we also see that the stability of self-assembled polyelectrolyte films is intimately related to that of complexes formed in the solution (coacervates), as has been stated in the literature, ${ }^{4}$ but seems largely ignored in many investigations.

\section{Conclusion}

The stability of PAH/PSS films, and more generally the stability of polyelectrolyte films containing at least one weak polybase or polyacid, is strongly dependent on $\mathrm{pH}$, due to the determining influence of electrostatic bonds between the two polymers. There is a critical $\mathrm{pH}$, above or below which the film breaks, releasing a large part of the polymers. There are two reasons for the destruction of the film: (1) when one of the polymer charge densities becomes too low, the binding strength of the molecular aggregates, which act as the elementary bricks of the film, is no longer sufficient and the film breaks and (2) when the charge of one polymer in the film decreases, the uncompensated charge of the other polymer creates a repulsive interaction between the molecules of that polymer, which induces a fast release of molecules. After the film broke, we found that the fraction remaining in the interface was the polymer bound electrostatically to the substrate and that the amount was close to, and just above, the monolayer formed by direct uptake from the solution. Our results show that the stability of self-assembled polymer films depends on two major factors: the strength of the binding between the surface and the polymer of opposite charges, which dominates at earlier steps of the buildup, and the strength of the binding between the two polymers in aggregates, which allows the cohesion of the film in later steps.

Acknowledgment. This work was supported by the EU under Contract NMP4-CT-2003-001428: Nanocapsules for Targeted Controlled Delivery of Chemicals. The authors are grateful to Nancy Richardson-Peuteuil for her editorial assistance. 